\title{
Teaching Art and History to Photonics students
}

\author{
José A. Martín-Pereda ${ }^{1}$ \\ E.T.S. Ingenieros de Telecomunicación. Universidad Politécnica de Madrid \\ Ciudad Universitaria. 28040 Madrid. Spain
}

\begin{abstract}
The case to be reported in this paper is the teaching of topics involving the relation among Photonics, its history, the international situation and the artistic movements in each period. These kind of new studies correspond to a new tendency in teaching interdisciplinary topics to students coming from different areas. Two main courses, one in History and other one in Art, will be taken as examples. Theses two courses have been taught for several years in Madrid, Spain, for Telecomm students and the results have been very satisfactory.
\end{abstract}

Keywords: Art, History, Interdisciplinary curricula.

\section{INTRODUCTION}

New curricula tend to be much more interdisciplinary than before. Students coming from different areas may follow courses with topics formerly located in careers without previous common points. This tendency is not just confined to technical areas where, for example, students in telecomm degrees may attend courses on biology or chemistry. Nowadays, students in technical careers attend courses on history or artistic subjects and vice versa.

Two are the main problems related with this tendency. The first one is that students coming from fields, where these type of subjects have not been taught, have a deficient knowledge of previous and needed topics. The second one is that, in many cases, they do not feel interest in the subject of the course and tend to relax. Moreover, teachers in many cases are deeply specialized in their own topic and they do not care about difficulties had by students coming from other areas. As a matter of fact, they do not care about the possible relations between their subject and other different subjects.

It is evident that the way to solve above indicated problems is difficult and, at the same time, is almost impossible to teach courses valid in both directions, that is, useful at the same time for humanistic and technical students. Moreover, the solution may be different for teaching humanistic courses to technical students or technical courses for humanistic students.

The main objective of this paper is to show some experiences had in the last years, in the Telecommunication School of the Madrid Politechnical University, in Spain. Two basic courses have been taught for five years, one of then trying to show the relations between history and some technical discoveries in the last two centuries and the other one trying to prove the influences of technical discoveries along the XX century on artistic movements. Both courses were not located in any particular level of the career and any student coming from any one of the five years of their degree could enroll.

A final point needs to be considered. It a common fact, at least in large universities where a large number of studies are offered, students may attend courses taught in other careers different from their own major. The Telecommunication School belongs to a Politechnical University where every one of the careers is technical and hence, professors and topics are just related with different branches of Engineering. This makes difficult to offer courses with humanistic topics. In some cases, some subjects have been offered having non-technical approaches. External professors were hired for this task. The final result was not satisfactory. The reason was twofold. A first reason was that professors with no technical background tend to explain their humanistic topics with a view no familiar for engineering students. The second one is that students tend to look to external professors as "second level" professors, teaching "second level" topics. The final result is that nobody, professors and students feel that the course was efficient and it was just a way to fulfill some number of credits. This situation changes if full professors, with a large technical curriculum behind them, teach these courses. Professors know the "technical language" and students feel that the topic must be important when an "engineer" devotes some of his time to it.

${ }^{1}$ jamp@tfo.upm.es 


\section{BASIS STRUCTURE OF THE COURSES OF HISTORY}

As it was pointed out before, different has to be the way to teach a topic depending on the previous curricula. In the present case, it was assumed, and that proved to be true, that the previous knowledge of Telecomm students about topics related with Art or History was almost inexistent. At the same time, the evolution of a certain technology along the years was not a matter of interest to them. Just the most recent achievements were, as usual, the object of their curiosity and the pole of attraction for their interest. In this way, when the courses were offered for the first time, it was necessary to choose some special points to attract their attention. Two different points were chosen for History and Art courses. In the first case, for a course about the relation between technical discoveries and History, the main idea was to indicate that the course would analyze the relations between technical leaps and international relations. This idea was of interest due to the fact, seen everyday at the media, that no nation is nowadays an island and that decisions adopted in supranational organizations, as UNO or EU, are of extraordinary importance for everyday activities. As lessons to be learned, the course would present particular cases where this type of situation was clearly established. The idea that some particular discovery was the result of the international relations had at a particular moment, was prompt captured by the students.

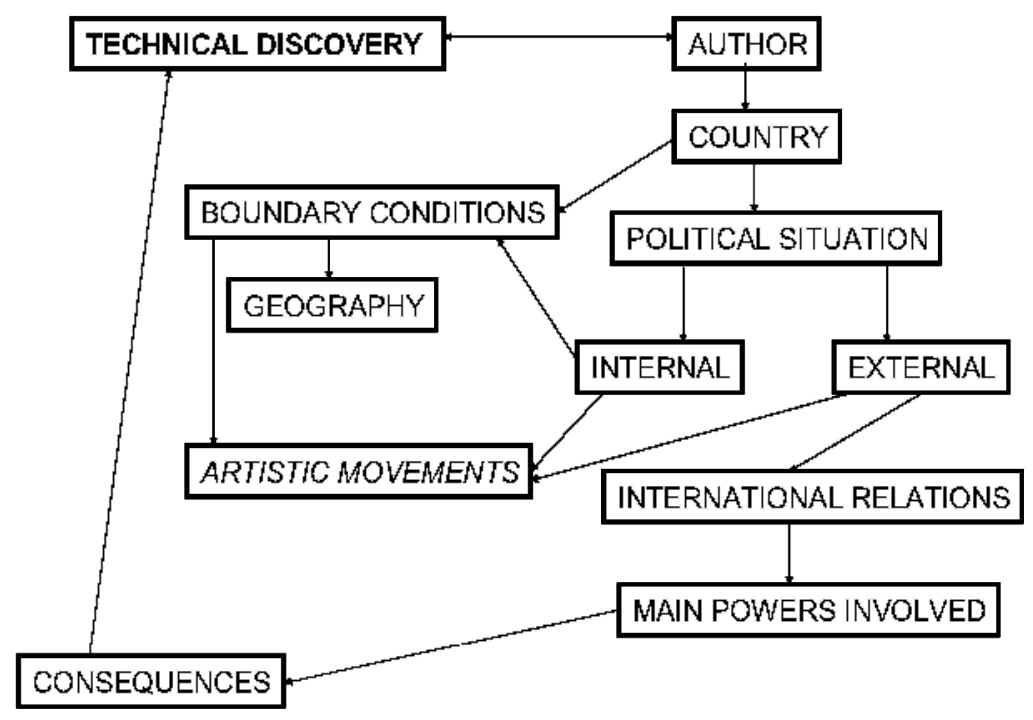

Fig. 1.- General structure for the teaching of a technical discovery

According to this idea, a general scheme for the cases to be analyzed appears in Fig. 1. It is obvious that this structure must be adapted to each particular case but it gives some of the main points to be considered. The internal and external situations of the country where the author developed his work have to be of prime interest for the analysis. This gives the "boundary conditions" for the problem to be presented. This aspects have to be related with other conditionings as, for example, the geography of that country, its economical situation, its relations with other countries, its balance of influences and, if possible, the existing artistic movements. In many cases, the personal story of the author may give some other insights on the whole scenario. These aspects, when put together, offer a complete panorama of the historical situation where that particular discovery was preformed.

As an example, the case of the optical telegraph, by Claude Chappe, may clarify these concepts.

The general structure for the story of the French Engineer Claude Chappe is shown in Fig. 2. Some of the blocks in Fig. 1 have been covered with the more significant aspects. The reason why the optical telegraph was developed in France, instead in any one of the European countries with similar scientific status, is explained to be due to the political situation of France at that time. France was in the first years of the Revolution. The political system to be developed was in conflict with every one of the regimes had in the countries around France, absolute monarchies. Moreover, France is in the middle of Europe and distances between Paris, where the National Assembly was, and the frontiers imposed a long 


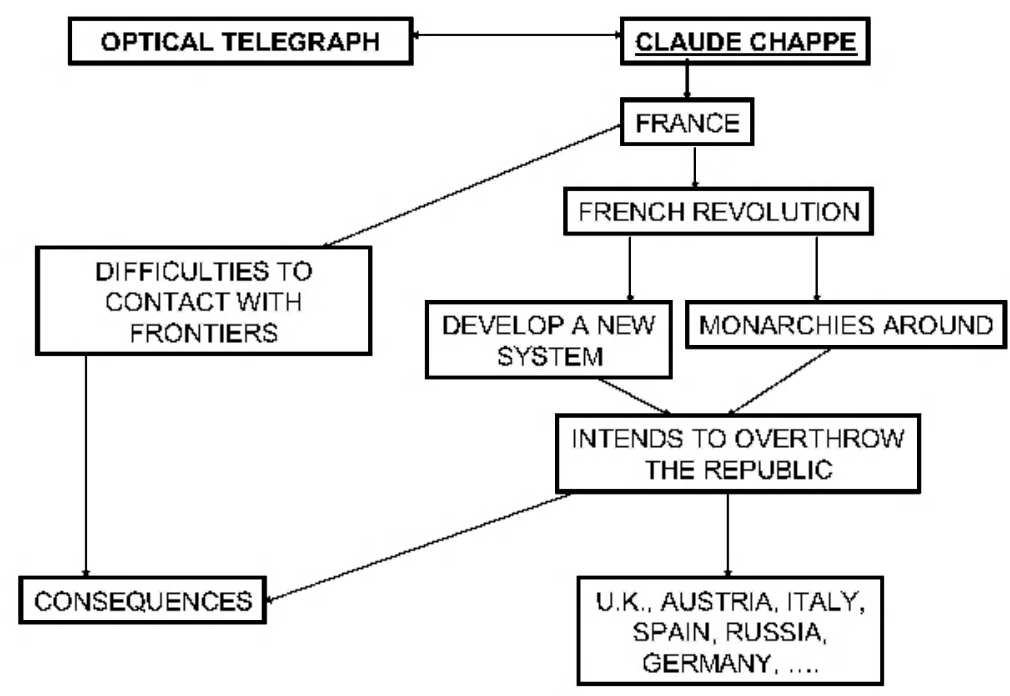

Fig. 2.- General structure of the Optical Telegraph discovery.

journey, more than two days. The French army, although with a similar level to the armies of other nations, needed to be prepared to fight along long boundaries and move from one place to another depending on the external situation. The conventional communication systems had by then, could not satisfy these conditions. At the same time, internal fights with followers of the "Ancien Régime" imposed the need to change security forces from one place to another. Sending orders and receiving information, at a faster speed that before, was a need to survive. It is because that the National

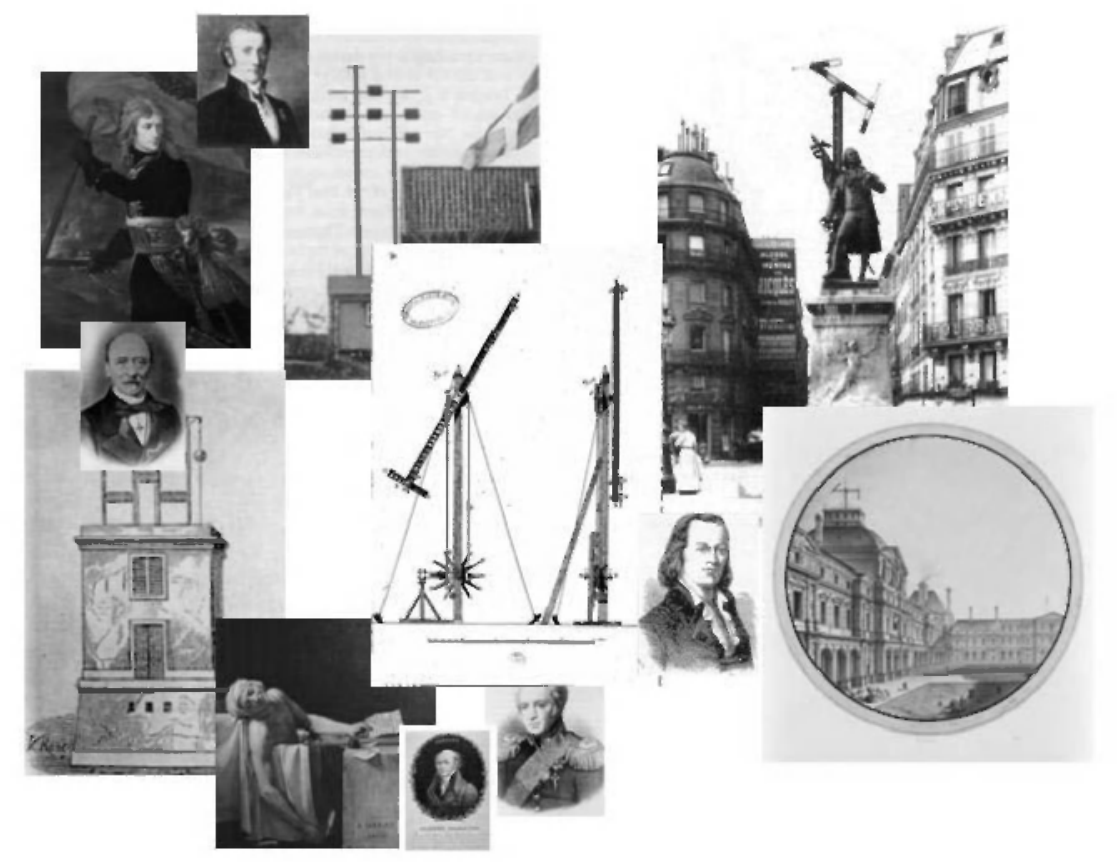

Fig. 3.- Collage with some of the graphic material shown for the Optical Telegraph. 
Assembly gave money and priority to the optical telegraph. And so, the first optical telegraph was born.

At the same time than these facts are presented to the students, some connections with similar discoveries in other European countries are reported too. In this way, developments had in Sweden, with Abraham Edelcrantz, or in Great Britain, with George Murray, or in Spain, with Agustin de Betancourt and Jose M. Mathe, are shown as a part of a general tendency towards a new type of communications. The reasons why these models got a minor diffusion than the Chappe's, due to political and economical reasons, offered new insights into the history of Europe in the first decades of the XIX century. Some of the graphical illustrations presented to the students appear in the collage of Fig. 3. This figure shows also some artistic works, as the ones showing Danton and Napoleon, as a part of the connection of Technology and History with Art. Some other references to literature paragraphs, where authors as T. Carlyle or Victor Hugo make

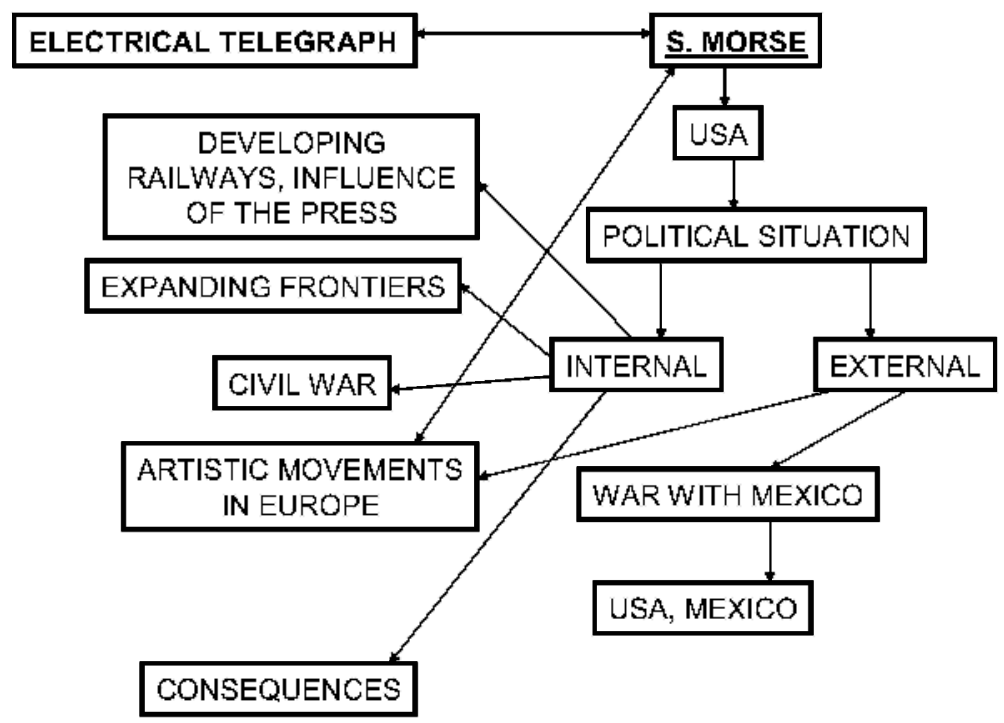

Fig. 4.- General structure of the Electrical Telegraph discovery.

references to the optical telegraph, are given too.

Other example of this part of the course is the discovery of the electrical telegraph by S. F. Morse. Its general structure appears in Fig. 4. This structure is similar to the previous one, the one employed with Chappe. But a deeper analysis of the artistic movements are possible now than in the previous case. This is due to the fact of the initial Morse career, professor of Art in New York. Due to his work, he had to go to Europe in several occasions. And at the same time that he visited the Louvre, he saw how the optical telegraph worked. Talks with different people gave him a new vision of recent discoveries in Electricity. He got his conception of the electrical telegraph from these ideas and in the way back to the States he drew the first sketches. In his country, the internal situation was, mainly, an increasing power of the press and the expansion of new frontiers to the west. The press demanded more speed to transmit news and the way to the west, with an increasing number of railroads, asked for safer methods to control the trains. The only solution to these problems was a new method to transmit information. And so the electrical telegraph got his way open. Moreover, the war with Mexico and the following Civil War demanded a better information transmission. New companies were created and the basis for the future structure of communications established. These facts allow introducing the different states forming the Union, how they expanded to the west and how they communicated with Europe. In the same way than the story of the optical telegraph allowed to teach some of History of Europe, the electrical telegraph allow to teach the history and geography of the United States. Moreover, it show the different conceptions had by Europe and the States with respect to the communications infrastructure. Due to their origins, communications in Europe were a responsibility of governments whereas in the States were in private hands almost from the beginning. 


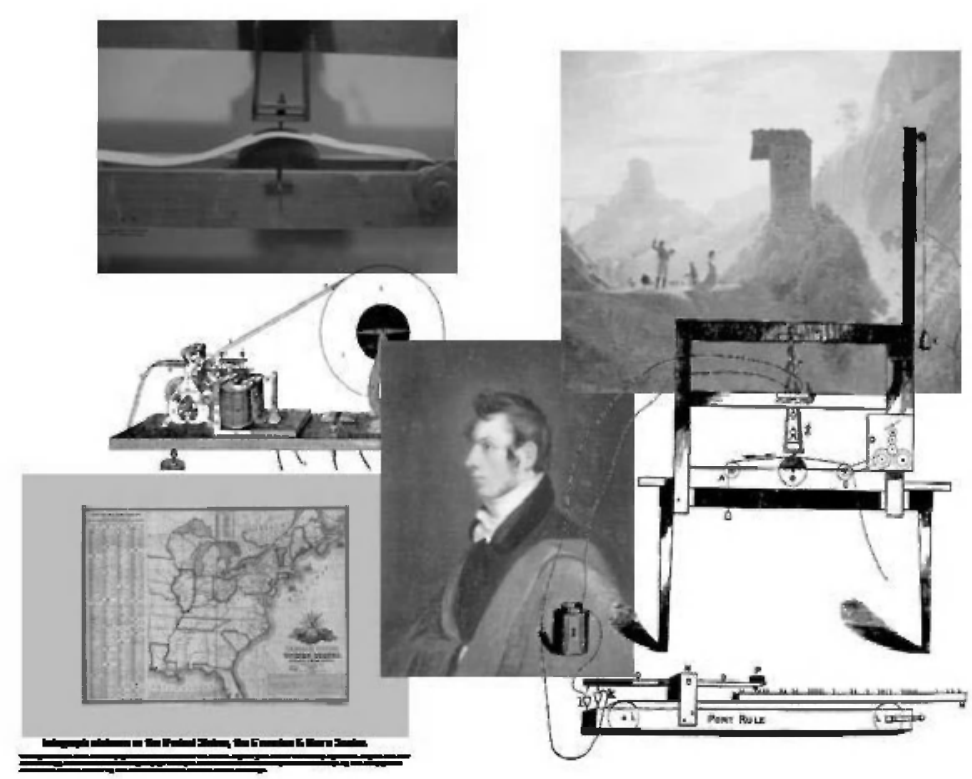

Fig. 5.- Collage with some of the graphic material shown for the Electrical Telegraph.

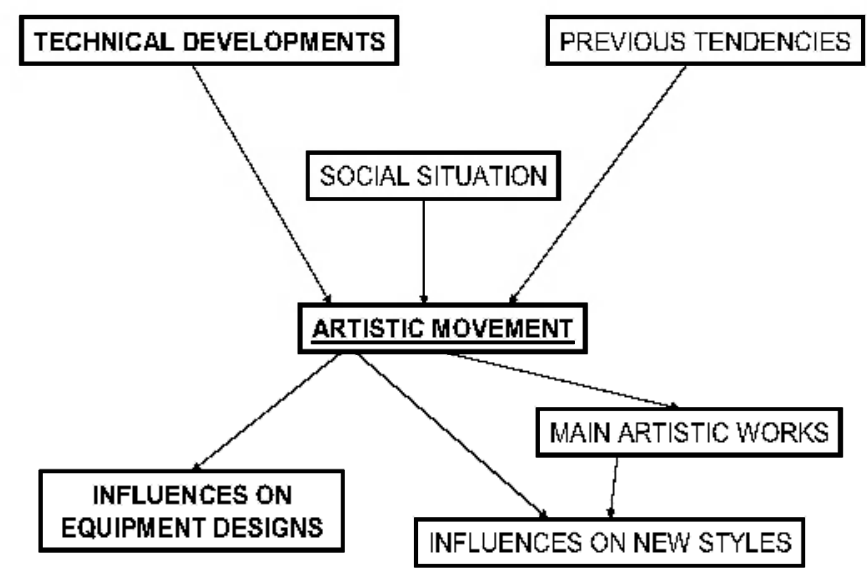

Fig. 6.- General structure for the teaching an artistic movement.

Some other examples, as the case of the Telephone and the Photophone by Graham Bell, the Marconi adventure and the first years of laser, cover other lectures in the course. An index of main topics appears in Appendix B. Some Lectures Notes has been published ${ }^{1}$ and the final chapter in a recent book ${ }^{2}$ is fully devoted to this topic. 


\section{BASIS STRUCTURE OF THE COURSES OF ART}

In the case of courses centered on the relation between a particular technological situation and the artistic movements had at that time, the motor idea must be modified with respect to the previous one. The central objective is not now a scientific or a technical discovery but an artistic movement and its relations with recent technical achievements. It is obvious that the relations between these two activities of society are strongly dependent on the analyzed interval of time. In some cases, this relation is almost inexistent or the influence less clear. But in some others there are strong ties between them. The course is just centered on those time intervals where the relation and the advantages of the interrelation are clear. Moreover, in the course taught last year, the idea was to move towards a situation close to the present time as much as possible. This election has a main advantage. It is the possibility to see examples still alive in the daily life.

The main structure of each studied case appears in Fig. 6. As it may be seen, two are now the possible interaction between art and technology. The first one is the influence of technical or scientific discoveries on artistic works. For instance, the discovery of perspective was one of the main engines in painting during Renaissance in Italy. At the same time, the reverse way is possible too. The introduction of perspective in painting opens new fields for optical research. One of them is, for example, the study of the reasons why people see a similar object with different characteristics, mainly dimensions, according to the place where it is.

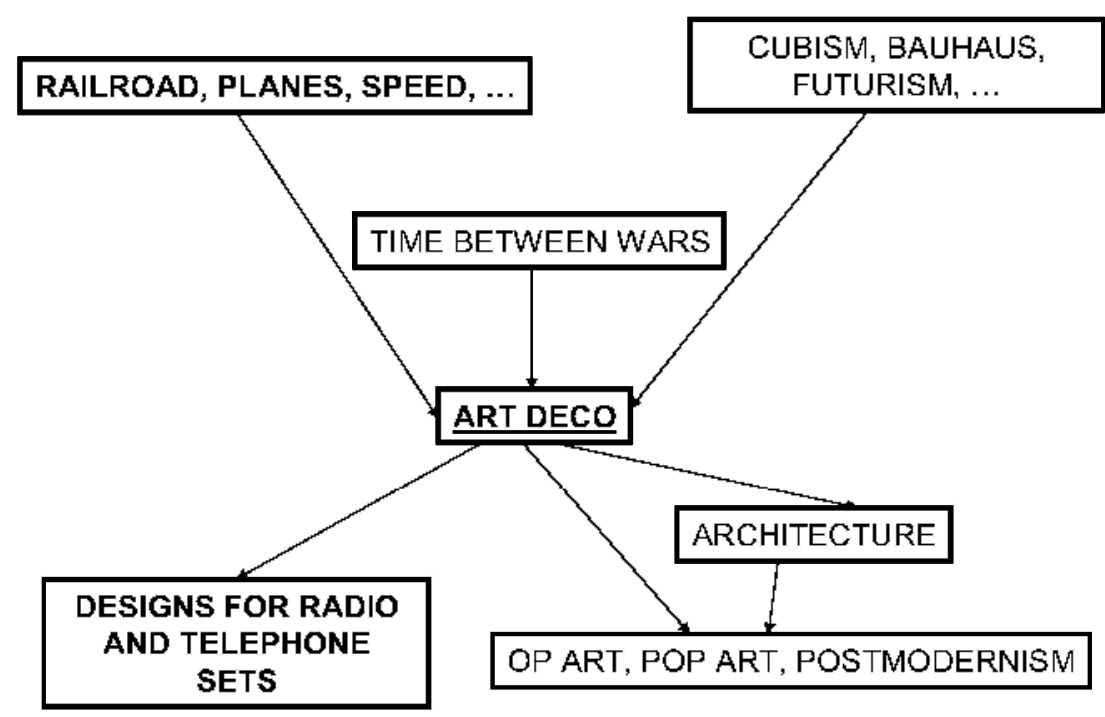

Fig. 7.- General structure for the teaching of Art Deco and its relation with the technical achievement of 1910-1940.

The case to be studied was the relations between Art Deco and the introduction of new technical discoveries. This time interval, mainly from 1910 to 1940 , opened a large variety of topics still around us. The general structure of the course is shown in Fig. 7. A program for the lectures appears in Appendix B. Art Deco, as a matter of fact, is just an excuse for the introduction of the large series of artistic movements appearing, mainly in Europe, from the last years of the XIX century to the end of the World War II. To explain the time around the twenties and the thirties need to go into its roots. And these roots are in the World War I, in the avant-gardes and in the new technologies appearing from the beginning of the XX Century. Because the students are engineering students, in most of the cases their knowledge of these topics is almost null. It is necessary to go backwards and start from some years in the past. As a matter of fact, in many cases they even do not know the differences between the several "isms" had in art from the last years of the XIX Century. At the same time, in History, the years between the two World Wars are like a black hole for them. 
In the case of Telecommunication students, as it is the case, the main points to be studied are the different designs had in electronic equipment and how these designs are influenced by Art Deco. Some of the graphic material employed for classes is shown in Fig. 8. Concepts as speed, herzian waves, steam and telephony, main actors those years, are shown how were influenced by art and technology.

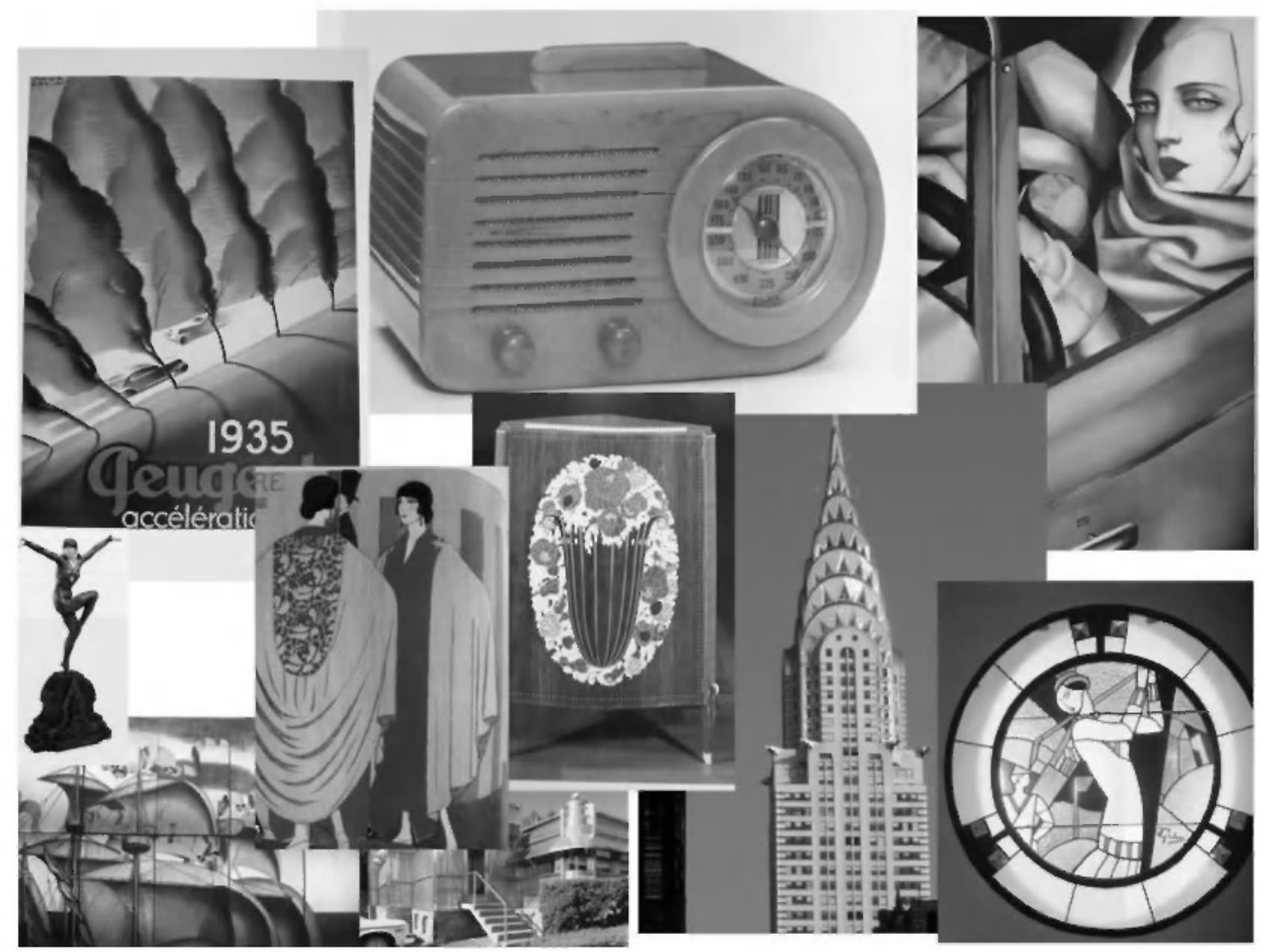

Fig. 8.- Collage with some of the graphic material employed for teaching the relation between Art Deco and the technical discoveries in the first decades of XX century.

As a complement to above concepts, some visits were indicated to the students. The first one is the visit to the History of Communications Museum, located at the University, and to Telefónica Museum, hold by the main telephone company in Spain. They may see over there the differences in design had, for example, in telephone receivers from the beginning of the XX Century to the beginning of World War II. The second visit is just walking through different places in Madrid to locate and analyze some Art Deco buildings.

The result of the course was very good and everybody, students and instructor, recognized that was one of the courses followed with greater attention from the beginning to the end.

\section{CONCLUSSIONS}

The importance of an interdisciplinar curriculum is recognized as a very important factor to for future professionals. We are in very fast changing world and future professionals need to hold a wide background to adapt to any circumstance. As a consequence, it is necessary to offer different courses to the students where the relations between the many issues appearing in Society are present. No isolated factor is possible in any social, historical or technological development. All of them are interrelated and all of them are the result of many interactions and many trial and error tendencies. If the knowledge of different branches of Science and Technology is important to develop further advances in them, this principle may be applied to the knowledge of some other areas in Humanities. This has been the goal in these courses thought to these engineering students.

One of factors learnt from this kind of courses is the importance of the instructor. He or she has to know the topic. But at the same time he or she has to be a recognized professional in the field where these courses are taught. It is the only way the students consider the subject no just a matter to get credits but an important contribution to their future 
professional career. In this line, it is important to follow a didactical method similar to the one employed with technical topics. This aspect is very difficult to be fulfilled by an instructor coming directly from humanistic careers.

Finally, these ideas may be applied in the opposite direction: teaching of technical matters to students in nontechnical careers. But this problem needs another different way to be implemented.

\section{ACKNOWLEDGMENTS}

This work was partly supported by CICYT, grant TIC2003-04309.

\section{REFERENCES}

1. J.A. Martín-Pereda, "PÁGINAS PARA UNA HISTORIA DE LAS COMUNICACIONES ÓPTICAS Y LA FOTÓNICA". Dpto. Publicaciones. ETSIT-UPM. May, 2001.

2. J.A. Martín-Pereda, "SISTEMAS Y REDES ÓPTICAS DE COMUNICACIONES". Chapter 15. Pearson-Prentice Hall. Madrid. 2004.

\section{Appendix A: "ELECTRONIC FUNDAMENTALS OF COMMUNICATIONS"}

1. Introduction

2. Optical telegraphs in Europe. Chappe and the French Revolution. Optical telegraphs in England, Sweden and Spain.

3. From Optics to Electricity. Morse.

4. Alexander Graham Bell: Electric telephone and the Photophone. The first optical devices.

5. The beginning of the quantum theory. Einstein.

6. Radar concepts in the maser. From the World War II to the Cold War.

7. The need to go to higher frequencies.

8. The laser in the sixties. Changes in society and changes in technology.

\section{Appendix B: “ART DECO. INDUSTRIAL DESIGN IN COMMUNICATION SYSTEMS (1900-1939)"}

1. Introduction

2. Antecedents in the XIX century.

3. Art Nouveau. Art Nouveau in France and Belgium. German Jugendstil. Viennese Secession and Spanish Modernismo.

4. Avant-garde movements in the first decades of the XX century. Great War

5. Beginning of Art Deco in France. Art Deco in the United States. Influences from other cultures. Utilitarism. Totalitarisms.

6. Influence on architecture and textile design. Printing and engraving.

7. Mass production of domestic tools. Introduction of new materials.

8. Design of radio and telephone sets. Ads in audiovisual media with new technological concepts.

9. Second World War.

10. Opt Art and Pop Art.

11. Concepts of Art Deco in Post-Modernism. 